\title{
Una frustrada evangelización: \\ las limitaciones del cambio social, cultural y religioso en los "pueblos errantes" de las misiones del desierto central de Baja California y la región de la costa del Golfo de Texas
}

\author{
Robert H. Jackson \\ State University of New York, Oneonta \\ Traducción de Camilo Hoyos \\ Corrección de estilo Víctor Albarracín
}

\begin{abstract}
Resumen
Las misiones religiosas fueron parte fundamental de la política de dominación de la corona española sobre los indígenas en América. Sin embargo, no en todos los casos se encontraron comunidades sedentarias, que permitiera un rápido sometimiento y cristianización. En las zonas desérticas de la Baja California y la costa del Golfo de México, los misioneros jesuitas, dominicos y franciscanos intentaron establecer, con poco éxito, comunidades estables basadas en la agricultura, que permitieran la congregación de los pueblos errantes de la zona y el desarrollo de la evangelización. A partir de este caso, el artículo analiza las limitaciones del proyecto misional como vehículo de la política colonial.
\end{abstract}

\begin{abstract}
The religious missions were a fundamental part of the politics of domination of the indigenous population of the Americas by the Spanish Crown. However, the missionaries did not always encounter sedentary communities, that allowed rapid subjugation and Christianization. In the desert zones of Baja California and the Gulf Coast of Texas, the Jesuit, Dominican, and Franciscan missionaries attempted to establish, with little success, stable communities based on agriculture, that would have allowed for the congregation of the "wandering peoples" of the zone and the development of evangelization. Based on these cases, the article analyzes the limitations of the missionary project as a vehicle for colonial policies.
\end{abstract}


El sistema colonial español funcionaba relativamente bien en las áreas ocupadas por sociedades indígenas avanzadas, como en México central, donde podía reemplazar los sistemas estatales existentes y modificar, dependiendo de sus necesidades, determinadas instituciones establecidas, como por ejemplo el tributo. El dominio de los nativos le resultaba más difícil y potencialmente costoso a una parsimoniosa corona española en los márgenes de las sociedades indígenas avanzadas y sedentarias. Los conquistadores ${ }^{1}$ encontraban pocos beneficios al tratar de subyugar a cazadores-recolectores nómadas o a agricultores semi-sedentarios que carecían de grandes acumulaciones de provisiones y no tenían claramente delineada una forma de autoridad que los españoles pudieran reemplazar para asumir el control. Por otra parte, muchas áreas de los asentamientos españoles en el Nuevo Mundo no tenían recursos valiosos (minas, por ejemplo) que pudieran ser explotados para producir riqueza o ingresos a través de los impuestos.

Fue en las fronteras del imperio donde la misión surgió como una importante institución colonial, ya que demostró ser una manera efectiva de transformar a los nativos en lo que los españoles querían. El modelo de comunidades indígenas políticamente autónomas, que podían ser aprovechadas como un mercado potencial, una fuente de trabajo y una posibilidad de ingreso mediante el pago de tributos, funcionaba bien en el esquema español de gobierno indirecto. El propósito de la misión era transformar a los indígenas en agricultores sedentarios que pagaran un tributo, proveyeran trabajo y fueran cristianos en conformidad con las normas religiosas españolas del Catolicismo. A pesar de que este plan fue diseñado en distintos términos, según las diferentes regiones, el modelo básico fue muy parecido allí donde el gobierno español introdujo la institución.

Aunque el proyecto era, en teoría, muy bueno, la relación entre la aplicación de los propósitos y la institución como tal no siempre funcionaba. Una serie de factores influyeron negativamente en los resultados de las transformaciones culturales, sociales y religiosas en las misiones. Entre estos factores se incluyen la hostilidad de los nativos, tanto de los que participaban como de los que permanecían fuera de la misión, las áridas tierras donde la agricultura era imposible, y el fracaso de los misioneros en su intento por someter a su gusto a los indígenas, o, en otras palabras, de arrebatarles por completo el papel protagónico en el drama de su historia. Por lo general, los indígenas se negaron a reemplazar su modo de vida por la forma sedentaria que los misioneros esperaban establecer. Ciertamente, la historiografía reciente sobre la historia de las misiones en América Latina ha enfatizado, entre otros temas, las formas en que los pueblos

\footnotetext{
${ }^{1}$ [Las palabras resaltadas en cursiva están en castellano en el original. Nota del traductor]
} 
indígenas jugaron un papel activo al rehacer su mundo y al limitar las acciones de los misioneros que intentaban por todos los medios conseguir sus propósitos. ${ }^{2}$

¿Qué tan fructífero resultó el proyecto misional en unas condiciones tan adversas como la aridez de las tierras, la hostilidad de los nativos y el rechazo de los indígenas a la vida sedentaria? Este estudio examina las misiones establecidas por jesuitas, franciscanos y dominicos entre un grupo conocido genéricamente como los Cochimi en la región del Desierto Central de Baja California, una de las regiones más áridas del norte de México, y los Karakawas en las costas del Golfo de México en Texas, a lo largo del Bajo Río San Antonio. Estas regiones exigieron las habilidades y la paciencia de los misioneros, y muestran de una forma muy gráfica las limitaciones de la misión como vehículo de la política colonial de España. Estos dos estudios muestran lo que pudo ser llamado el peor episodio en la historia de las misiones, visto desde la perspectiva española.

Aunque casi toda la Baja California es seca, el Desierto Central, que se encuentra en la actual frontera entre Baja California Sur y Baja California, es sin lugar a dudas la región más seca de toda la península. Se encuentra agua en pequeñas piscinas, pero con la excepción del oasis de San Ignacio, ninguno de los sitios escogidos por los misioneros permitía la agricultura, practicada al estilo mediterráneo por los españoles. ${ }^{3}$ El Desierto Central era esencialmente un obstáculo geográfico que debía ser superado por los jesuitas para alcanzar, en el norte, las hospitalarias costas de California. Una inmensa población indígena que no había sido controlada podía ser una amenaza para las

\footnotetext{
${ }^{2}$ Notables trabajos sobre este tema incluyen: Erik Langer y Robert Jackson, eds., The New Latin American Mission History (Lincoln: University of Nebraska Press, 1995); David Block, Mission Culture on the Upper Amazon: Native Tradition, Jesuit Enterprise, and Secular Policy in Moxos, 1660-1880 (Lincoln: University of Nebraska Press, 1994); Randall Milliken, A Time of Little Choice: The Disintegration of Tribal Culture in the San Francisco Bay Area, 1769-1810 (Menlo Park: Ballena Press, 1995); Robert H. Jackson, Indian Population Decline: The Missions of Northwestern New Spain, 16871840 (Albuquerque: University of New Mexico Press, 1994); Jackson y Castillo, Indians, Franciscans, and Spanish Colonization: The Impact of the Mission System on California Indians (Albuquerque: University of New Mexico Press, 1995); John Worth, The Timucuan Chiefdoms of Spanish Florida, 2 vols. (Gainesville: University of Florida Press, 1998); Jerald Milanich, Laboring in the Fields of the Lord: Spanish Missions and Southeastern Indians (Gainesville: University of Florida Press, 1999); Robert H. Jackson, Race, Caste and Status: Indians in Colonial Spanish America (Albuquerque: University of New Mexico Press, 1999); James S. Saeger, The Chaco Mission Frontier: The Guaycuruan Experience (Tucson: University of Arizona Press, 2000). Esta lista no es en absoluto exhaustiva.

${ }^{3}$ El estudio más detallado sobre la ecología del Desierto Central es de Homer Aschmann, The Central Desert of Baja California: Demography and Ecology (Berkeley y Los Angeles: University of California Press, 1959).
} 
comunicaciones, una vez que, finalmente, comenzó la proyectada colonización de California.

Los jesuitas escribieron relativamente poco acerca de los pueblos nativos del Desierto Central, pero sabemos claramente que eran, tomando prestado un término acuñado en un reciente estudio sobre el desierto de Sonora, "pueblos errantes," localizados en el Golfo de California, en Baja California. ${ }^{4}$ Los habitantes del Desierto Central vivían en pequeños grupos, generalmente familiares, y tenían un patrón de migración estacional que les permitía explotar distintos recursos alimenticios. En 1744, Sebastián de Sistiaga, S.J., de la misión de San Ignacio (establecida en 1728), notó que los indígenas comían frutos de cactus durante el verano y el otoño, y para el invierno y la primavera utilizaban otros recursos de comida. Los nativos tenían un sistema de creencias representado mediante arte rupestre que se encuentra en diferentes partes del Desierto Central; son dibujos en los cuales los chamanes tenían una importante función como curanderos e intermediarios con el mundo de los espíritus. Sistiaga y otros jesuitas desecharon las creencias religiosas de los indígenas, tomándolas como "errores y supersticiones," y llamaban a los chamanes hechiceros. ${ }^{5}$

A pesar de que los jesuitas, y luego los franciscanos y dominicos, ${ }^{6}$ bautizaron a miles de nativos, la mayoría de los neófitos no podían ser mantenidos en la aldea principal de la misión (cabecera), por lo que residían en sus asentamientos tradicionales, que los misioneros, eufemísticamente, llamaron visitas. Casi todos estos asentamientos satelitales eran subdesarrollados, y los misioneros no tenían intenciones de cambiarlos.

\footnotetext{
${ }^{4}$ Cynthia Radding, en su libro Wandering Peoples: Colonialism, Ethnic Spaces, and Ecological Frontiers in Northern Mexico, 1760-1850 (Durham: Duke University Press, 1997), utilizó el término pero no explicó la manera como los patrones de migración estacional afectan la aplicación de los proyectos misionales. [El término en inglés es "Wandering Peoples." Nota del traductor]

${ }^{5}$ El informe de Sistiaga está publicado en Ernest Burrus, S.J., Jesuit Relations: Baja California (Los Angeles: Dawson's Bookshop, 1984).

${ }^{6}$ Los jesuitas iniciaron la colonización de Baja California en 1697 luego de numerosos planes fallidos de colonización impulsados por el gobierno. Bajo el acuerdo establecido con éste, los jesuitas buscaron dotaciones de fuentes privadas para establecer las misiones en la Península. La expulsión de los jesuitas en 1767 fue llevada a cabo en California a principios de 1768, y franciscanos de la Universidad Apostólica de San Fernando en Ciudad de México, liderados por Junípero Serra, O.M.F., asumieron la responsabilidad de todas las misiones de la Península. En 1768-1769, el Visitador general estaba en Baja California para reformar las misiones, y en 1769 Gálvez organizó la expedición que tenía como fin ocupar San Diego y Monterrey en California. En 1773, los franciscanos cedieron las misiones de la Península a los dominicos para así concentrarse en las misiones de California. Los dominicos permanecieron en Baja California hasta la década de 1840 .
} 
En 1755, por ejemplo, la misión Santa Gertrudis (establecida en 1751) contaba con más de 1,500 indígenas, pero sólo residían 69 en la cabecera. El resto de la población vivía en ocho aldeas que se trasladaban de sitio según las estaciones. ${ }^{7}$ Dos décadas después, en 1773, la población de Santa Gertrudis reportó en total 1,000 neófitos, pero sólo 141 residían en la cabecera. ${ }^{8}$ Francisco Palou, O.M.F., misionero franciscano, describió en 1771 el patrón de asentamiento de Santa Gertrudis en términos también utilizados para describir las otras misiones del Desierto Central:

De todas estas familias sólo cuarenta familias viven en la misión con ciento setenta y cuatro almas. El resto están esparcidas en siete rancherías sin casas que rodean la misión en todas las direcciones, todos buscando frutos salvajes y cambiando según las estaciones. $^{9}$

Los misioneros traían periódicamente a los neófitos de asentamientos periféricos a la misión durante cortos periodos de instrucción religiosa, pero luego los devolvían a su tradicional forma de vida, con tan sólo - si les iba bien- una apariencia de la cristiandad. A pesar de los numerosos inconvenientes en la labor de evangelización, los misioneros escribieron confidencialmente, en un tono de auto felicitación, acerca de la profundidad de la conversión de los nativos. En su reporte de San Ignacio en 1744, Sistiaga notó que: "Ellos [los neófitos] abandonan, junto con los muchos errores y supersticiones, sus creencias acerca de los engaños y fábulas diabólicas." ${ }^{10}$ No sobra decir que Sistiaga y los otros misioneros no sabían lo que sucedía mientras los neófitos estaban solos, sin supervisión alguna.

En el transcurso de cinco décadas los jesuitas, y luego los franciscanos, establecieron seis misiones en el Desierto Central: Guadalupe (1720); San Ignacio (1728); Santa Gertrudis (1751); San Francisco de Borja (1762); Santa María (1766) y San Fernando (1769). Luego del establecimiento de la misión San Ignacio, les tomó más de dos décadas fundar la siguiente misión, inclusive teniendo los fondos disponibles para una nueva dotación. Una de las muchas dificultades fue localizar un lugar apropiado que

\footnotetext{
${ }^{7}$ Joseph de Urera, S.J., Nuevo estado de las misiones de esta prov[inci]a de la Comp[añí]a de Jesús de Nueva España, University of Texas at Austin, General Libraries, W. B. Stephens Collection.

${ }^{8}$ Gregorio Amurrio, Entrega de esta Misión de S[an]ta Gertrudis, Santa Gertrudis, 4 de junio de 1773, Archivo General de la Nación, México, D.F., Misiones, 12.

${ }^{9}$ Citado en Zephyrin Engelhardt, O.M.F., Missions and Missionaries of California: Lower California (Santa Barbara: Mission Santa Barbara, 1929), 483.

${ }^{10}$ Citado en Burrus, Jesuit Relations, 123.
} 
tuviera agua y tierra arable. Inicialmente los jesuitas planearon llamar a esa nueva misión Dolores del Norte, a instancias de la congregación de Nuestra Señora de los Dolores en Ciudad de México, quienes proveyeron la dotación. Informes de la década de 1740 se referían a Dolores del Norte como una misión incompleta.

Dos informes de la década de 1740 proveen detalles adicionales acerca de los esfuerzos para establecer lo que luego se llamó Santa Gertrudis, y resaltan la dificultad de localizar sitios adecuados en el Desierto Central. El primero es un informe de Sebastián de Sistiaga, S.J., misionero de San Ignacio, en el que señaló que Dolores del Norte fue un vástago de San Ignacio, formado por "asentamientos [de indígenas] del norte del interior." Konsag había bautizado 548 indígenas que serían asignados para la nueva misión, y los indígenas ya bautizados habían empezado a formar asentamientos nuevos y más grandes que se anticipaban a la misión. Para facilitar el proceso de evangelización, Konsag llevó jóvenes a San Ignacio para que fueran entrenados como catequistas y como futuros líderes de la nueva misión. El sitio que había sido tentativamente escogido para Dolores del Norte era seco y tenía poca agua, pero no se había encontrado nada mejor. Finalmente, Sistiaga señaló que una de las causas para la demora en fundar San Ignacio había sido la incertidumbre respecto a los cultivos. ${ }^{11}$ En un informe general de las misiones de Baja California, el Visitador General Juan Antonio Balthasar, S.J., señaló que: "Esta pequeña propiedad de la misión, incorporada a la de San Ignacio, será separada en cuanto esta misión se haya establecido por completo." 12

Konsag concretó las bases para la fundación del asentamiento de Santa Gertrudis en la década de 1740. El registro bautismal superviviente de San Ignacio (1743-1749) incluye los bautizos de cientos de indígenas, que Konsag realizaría en el futuro territorio de Santa Gertrudis. ${ }^{13}$ Ya en 1751, cuando los jesuitas empezaron a tener un registro sacramental independiente para el nuevo asentamiento, Konsag había bautizado 1,000 indígenas en la jurisdicción de Dolores del Norte/Santa Gertrudis. ${ }^{14}$ Basándose en la fundación planeada por Konsag, Jorge Retz, S.J., el primer misionero establecido en Santa Gertrudis, completó en doce años el bautizo de la población indígena no cristiana o gentil. ${ }^{15}$ En 1762, Ignacio Lizasoin, S.J., Visitador General jesuita, señaló que Retz

\footnotetext{
${ }^{11}$ Ibid., 141-5

${ }^{12}$ Ibid., 215

${ }^{13}$ Robert H. Jackson, "Demographic Patterns in the Missions of Central Baja California," Journal of California and Great Basin Anthropology 6, no. 1 (1984): 91-112.

${ }^{14}$ Aschmann, Central Desert of Baja California, 166.

${ }^{15}$ Ibid., 166.
} 
había bautizado hasta el momento 1,446 gentiles en Santa Gertrudis, y el total de bautizos alcanzaba $2,059 .{ }^{16}$

A pesar de la extensa exploración del Desierto Central, Konsag jamás encontró un lugar adecuado para la nueva misión. Francisco Palou, O.M.F., escribió una concisa descripción del sitio eventualmente escogido para la misión de Santa Gertrudis:

La misión está situada en un angosto valle, por lo que fue necesario despejar la tierra con palancas para poder construir un pueblo... Tiene viñedos y huertos de higos, olivas, granadas y también algunos duraznos. Hay poca tierra adecuada para sembrar y el agua es escasa. $^{17}$

Los misioneros asignados para los asentamientos en el Desierto Central tuvieron que enfrentarse con regiones sumamente áridas. Los franciscanos que se encontraban en las misiones, entre los Karankawas, se enfrentaron a un reto mucho mayor que el que significaban los mismos indígenas. Esta discusión se enfoca en Rosario, misión establecida en 1754 por el franciscano Juan de Dios María Camberos, O.M.F. Durante tres décadas los españoles trataron de mantener el control en la costa del golfo, para así prevenir los intentos de los franceses por re-establecer una colonia desde Louisiana. En 1722, los españoles crearon la misión Espíritu Santo, y un puesto militar cerca al lugar donde los franceses, liderados por La Salle, trataron infructuosamente de asentar su colonia tres décadas antes; luego los españoles trasladaron dos veces la misión, hasta que se decidieron, en 1749, a fundarla al lado del Bajo Río San Antonio, cerca al lugar donde Camberos hubiera asentado la misión cinco años después. ${ }^{18}$

Las bandas llamadas genéricamente Karankawas ocupaban una región que iba desde la Bahía Lavaca hasta la Bahía Galveston, en la costa tejana del Golfo de México. Los Karankawas eran cazadores-recolectores, se establecían en aldeas permanentes y tenían un claro patrón de migración estacional que les facilitaba explotar distintos recursos alimenticios. Durante el otoño y el invierno los grupos Karankawas explotaban los estuarios y atrapaban peces como la corvina negra y las gallinetas. Los campamentos

\footnotetext{
${ }^{16}$ Ignacio Lizasoin, S.J., Noticia de la visita general de...esta Prov[inci]a de Nueva España, W. B. Stephens Collection.

${ }^{17}$ Citado por Engelhardt, Missions and Missionaries, 484.

${ }^{18}$ Herbert E. Bolton, "The Founding of Mission Rosario: A Chapter in the History of the Gulf Coast," The Quarterly of the Texas State Historical Association 10, no. 2 (1906): 113-39.
} 
que creaban durante el otoño y el invierno tendían a ser mucho más grandes. ${ }^{19}$ Durante la primavera, los Karankawas se establecían en campamentos más pequeños a lo largo de los ríos y riachuelos de la llanura, cerca de la costa. Se mantenían gracias a la caza y la recolección de frutos de plantas silvestres. ${ }^{20}$ Los Karankawas eran los dueños de su entorno, y conocían muy bien la geografía costera. A menudo, los franciscanos expresaban su desaliento ante la imposibilidad de los militares españoles para perseguir a los neófitos escapados, ya que aquellos no conocían muy bien la geografía de la zona, y por lo general carecían de botes. ${ }^{21}$

Un gran número de Karankawas se establecieron durante las estaciones en la misión Rosario, localizada en las afueras de su territorio tradicional. Un informe franciscano de 1767 acerca de las condiciones de las misiones en Texas, demostraba la sensación de frustración que los misioneros experimentaron, como resultado de su incapacidad para congregar de manera permanente a los karankawas, y también su falta de entendimiento de la cultura karankawa, ocasionada por el chauvinismo cultural de aquellos que llevaban túnicas grises:

Los indios con quienes esta misión fue fundada son los Coxanos, Guapitos, Carancaguas y Copanos. En este momento, de cualquier manera, hay muy pocos de la última mencionada, ya que casi todos están viviendo en el bosque o a lo largo de los bancos de tantos ríos que hay en estas partes, o se han unido a alguna tribu amistosa en la costa, situadas a trece o catorce millas de esta misión. El padre desea asistirlos en todas sus necesidades y sufrimientos, pero, a pesar de esto, todos estos indios, que son salvajes, indolentes y perezosos, y que son tan orgullosos y glotones que devoran carne que está sancochada, casi cruda y goteando sangre, prefieren sufrir hambruna, la desnudez y la inclemencia del clima, se dejan vivir libres e indolentes en los bosques o en las costas, donde se entregan a todo tipo de excesos, especialmente a la lujuria, al robo y al baile. ${ }^{22}$

El informe luego anotaba que:

\footnotetext{
19 Robert Ricklis, The Karankawa Indians of Texas: An Ecological Study of Cultural Tradition and Change (Austin: University of Texas Press, 1996), 70-1.

${ }^{20}$ Ibid., 101.

${ }^{21}$ Ibid., 118.

${ }^{22}$ Peter Forrestal, trad. y ed., "The Solís Diary of 1767," Preliminary Studies of the Texas Catholic Historical Society 1, no. 6 (1931): 1-42.
} 
La tarea de convertir e inducir a los indios a vivir en la misión ha sido difícil, y algunos de los que han vivido aquí se han ido de nuevo a las montañas, a los bancos de río o a la costa. $^{23}$

Finalmente, el autor del informe se lamentaba por la falta de apoyo de los militares:

Aún otra razón [de la deserción de la misión] es porque los oficiales militares se niegan a traerlos [a los fugitivos que ya se habían capturado] a la aldea o castigar a aquellos que se fugan y se niegan a perseguirlos y traerlos de nuevo. Cuando logran traer a algún fugitivo fallan en imponerle algún castigo que pueda servirles como control y que puede instigar el miedo de volver a escaparse de la misión. ${ }^{24}$

La población de Rosario fluctuaba de año en año, pero también cambiaba según las estaciones. Un ejemplo de la variación estacional puede ser visto en 1796, cuando la población osciló entre 148 residentes en octubre y 97 en diciembre, tan solo dos meses después. En junio del año siguiente las cifras aumentaron hasta $254 .{ }^{25}$ Los Karankawas iban y venían de la misión cuando querían, y pueden haber incorporado a Rosario como parte de su patrón de migración estacional. El registro bautismal de la misión Refugio, también creada para los Karankawas, muestra que los neófitos bautizados se ausentaban de la misión durante meses, e inclusive un año o más, para luego volver con niños que debían ser bautizados, ya que, quizás, no tenían una alternativa distinta a regresar a la misión durante los periodos de escasez. ${ }^{26}$ Los documentos que registraron el regreso de grupos Karankawas a la misión demuestran que este ocurría durante la primavera, especialmente en los meses de marzo, abril y mayo. Esta era la época del año en que los Karankawas se trasladaban al interior: las misiones no eran más que otra fuente de comida. $^{27}$

\section{La construcción de las misiones}

Aunque a veces ignorado por los estudiosos, el casco (el conjunto de edificios) de las misiones era un importante y dispendioso aspecto del proyecto misional. Los misioneros

\footnotetext{
${ }^{23}$ Ibid.

${ }^{24}$ Ibid.

${ }^{25}$ Robert H. Jackson, "Congregation and Population Change in the Mission Communities of Northern New Spain: Cases from the Californias and Texas," New Mexico Historical Review 69, no. 2 (abril 1994): 163-83.

${ }^{26}$ Ibid., 178

${ }^{27}$ Ricklis, Karankawa Indians of Texas, 163-7.
} 
no tenían que cambiar tan sólo las creencias y la forma de vida de los indígenas, sino que, adicionalmente, debían crear físicamente las comunidades, siguiendo los esquemas que se habían utilizado en la construcción de las ciudades coloniales de la América española. Es más, a finales del siglo XVIII el gobierno español expresó un considerable interés por la decencia moral de aquellos indígenas sujetos a la corona, interés que nació por los estilos de las edificaciones erigidas en las misiones. Los dormitorios para mujeres solteras, quienes eran consideradas por los españoles como sumamente promiscuas, y que por lo tanto debían ser segregadas, se convirtieron en una característica normal de las misiones (ver tabla 1). La iglesia, situada en lo que sería la plaza principal, debía ser el edificio más imponente de toda la misión, ya que su tamaño tenía como función impresionar a los neófitos indígenas, impresión que les mostraría la grandeza de la nueva religión. Las otras estructuras incluían residencias y oficinas para los misioneros, habitaciones para los neófitos y construcciones con funciones económicas, como graneros y talleres.

Los cascos de los establecimientos de Baja California y de la misión Rosario no se parecían a aquellos más conocidos de las misiones de California, que tenían complejos subdesarrollados en sus primeros días. Las edificaciones pasaban por unas fases de desarrollo hasta llegar a su forma definitiva, proceso que tardaba normalmente unas décadas. La primera fase traía consigo la construcción de edificios temporales. En un reporte de 1755, por ejemplo, se registró la construcción de edificaciones temporales en

Tabla 1

Informe de edificios construidos en la Misión Santa Gertrudis, 1794-1801.

\begin{tabular}{ll}
\hline Año & \\
\hline 1794 & Herrería y carpintería. \\
1795 & Pequeña estructura \\
1796 & Estructura en piedra con techo arqueado. Medidas:48 x 9 varas o 40.2 x 7.5 metros \\
1797 & Una fuente de piedra. \\
1798 & Estructura en piedra. Medidas: 7 x 6 varas o 5.9 x 5 metros. \\
1799 & Dique para almacenar agua y para el sistema de riego. \\
1801 & Dormitorio para mujeres solteras y jóvenes de edades avanzadas. Cuatro residencias para la \\
& población indígena. \\
\hline
\end{tabular}


Fuentes: Santa Gertrudis Mission Anual Reports, Archivo General de la Nación, México, D.F.; Engelhardt, Missions and Missionaries, 527.

Santa Gertrudis, que incluían una iglesia y residencia para los misioneros. Los edificios fueron construidos con agua, revestimiento y paredes de árboles pequeños clavados en el piso y cubiertos con lodo. La iglesia nueva debía tener una longitud de 25 varas (1 vara $=0.838$ metros). ${ }^{28}$ Luego de esto, los misioneros ordenaban la construcción con adobe o estructuras de piedra, materiales que eran más duraderos.

Aunque casi siempre eran los misioneros mismos quienes diseñaban y dirigían la construcción de las nuevas edificaciones, algunas veces contrataban albañiles de México para que hicieran dicha labor. El conocimiento arquitectónico de los misioneros era intuitivo o aprendido mediante libros. Esto podía generar desastres, como ocurrió en la misión Guadalupe de Baja California, en 1744. En febrero de 1744, Juan Antonio Balthasar, S.J, dirigió una visita oficial a la misión de Guadalupe, y describió la iglesia de la misión como "la mejor iglesia de California." "Avanzado el año, luego de una temporada de lluvias fuertes, la iglesia colapsó y mató a unos cien neófitos. ${ }^{30}$ Una década después, durante su visita a las misiones de la península, Joseph de Urera, S.J., señaló: "La residencia [del misionero de Guadalupe] es muy buena. La iglesia colapsó ahora hace [sic] seis años: alrededor de cien personas murieron. Ahora están terminando una nueva y más fuerte." 31

No todos los proyectos de construcción terminaron en desastres, y con el tiempo, las comunidades se pudieron erigir en zonas salvajes, como se demuestra a través del análisis de las misiones de Santa Gertrudis y Rosario. Las primeras descripciones de las edificaciones en Santa Gertrudis se encuentran en el informe de 1755 acerca de las condiciones de las misiones, ya citado anteriormente. El informe señala el progreso de la construcción de una iglesia que debía ser de 25 varas, construida con entretejidos y revestimientos, ${ }^{32}$ y que funcionaría a la vez como residencia para el misionero. Estas estructuras eran temporales, y luego debían ser sustituidas por edificios más duraderos. En 1771, Palou describió el casco en los siguientes términos:

\footnotetext{
${ }^{28}$ Urera, Nuevo estado de las misiones, W. B. Stephens Collection.

${ }^{29}$ Citado en Burrus, Jesuit Relations, 224.

${ }^{30}$ Miguel del Barco, S.J., Historia natural y crónica de la antigua California, ed. Miguel León-Portilla (México, D.F.: Universidad Nacional Autónoma de México, 1973), 261.

${ }^{31}$ Urera, Nuevo estado de las misiones, W. B. Stephens Collection.

${ }^{32}$ Ibid.
} 
Tiene [la misión de Santa Gertrudis] una iglesia de adobe y viviendas que están cubiertas con tejas. Ha terminado el trabajo de construir el pueblo con chozas de adobe para los indios. $^{33}$

La descripción de Palou muestra que las primeras estructuras permanentes en Santa Gertrudis eran de adobe, con tejados situados sobre vigas cubiertas con tierra comprimida. Este estilo de construcción era adecuado para el clima seco de la misión. Aparentemente, la misma iglesia se conservaba en 1793, pues es descrita en términos similares a los de 1771 .

Los dominicos reportaron una considerable actividad constructora en 1790, como está resumido en la tabla 1. Ellos dirigieron la reconstrucción de casi todo el casco de la misión, y muchos de los informes anuales mencionaban específicamente el reemplazo de viejas construcciones por nuevas. Como lo hicieron en muchas otras misiones de la península, en 1801, los dominicos mejoraron el control social a través de la construcción de dormitorios para mujeres solteras y muchachas con mayor edad. Esto respondía a una orden del Obispo de Sonora, orden que a su vez se debió a una mayor preocupación del gobierno real por el proceso de transformación de las poblaciones indígenas de América y la adopción de las normas morales europeas. La estructura en piedra, finalizada en 1796, no incluía una iglesia, aunque fuera una gran sección de los edificios existentes en el sitio de la misión. En cambio, el informe anual de 1796, señala que la edificación consistía en dos dormitorios, una sala (cuarto de recepción) y un dispensario. El informe está incompleto, pero no existe referencia alguna a la construcción de una nueva iglesia entre 1793 y 1801. Esto sugiere que la iglesia de adobe mencionada en 1793 se siguió utilizando hasta los primeros años del siglo XIX. Es más, esto también sugiere que los misioneros dominicos no completaron el proyecto de reconstrucción en piedra del casco de la misión.

El esquema de las estructuras de Santa Gertrudis (ver figura 1) sostiene esta interpretación. Hoy en día sobreviven cinco habitaciones de piedra que hacían parte de una serie de estructuras que formaban una gran "L," cuyo espacio central estaba entre dos paredes. Una de las construcciones que no sobrevivió, pero que fue identificada en las fundaciones, es una gran estructura que, aparentemente, es la iglesia de adobe mencionada en 1793. Los otros cuartos eran pequeños, y la capilla actual parece que no fue construida para reemplazar la iglesia de adobe. Basándonos en la descripción del

\footnotetext{
${ }^{33}$ Citado en Engelhardt, Missions and Missionaries, 484.
} 
informe anual de 1796, el cuarto que actualmente es la capilla pudo haber sido la sala o el dispensario, que empezó a ser utilizado como capilla una vez la iglesia de adobe comenzó a deteriorarse y resultó inservible.

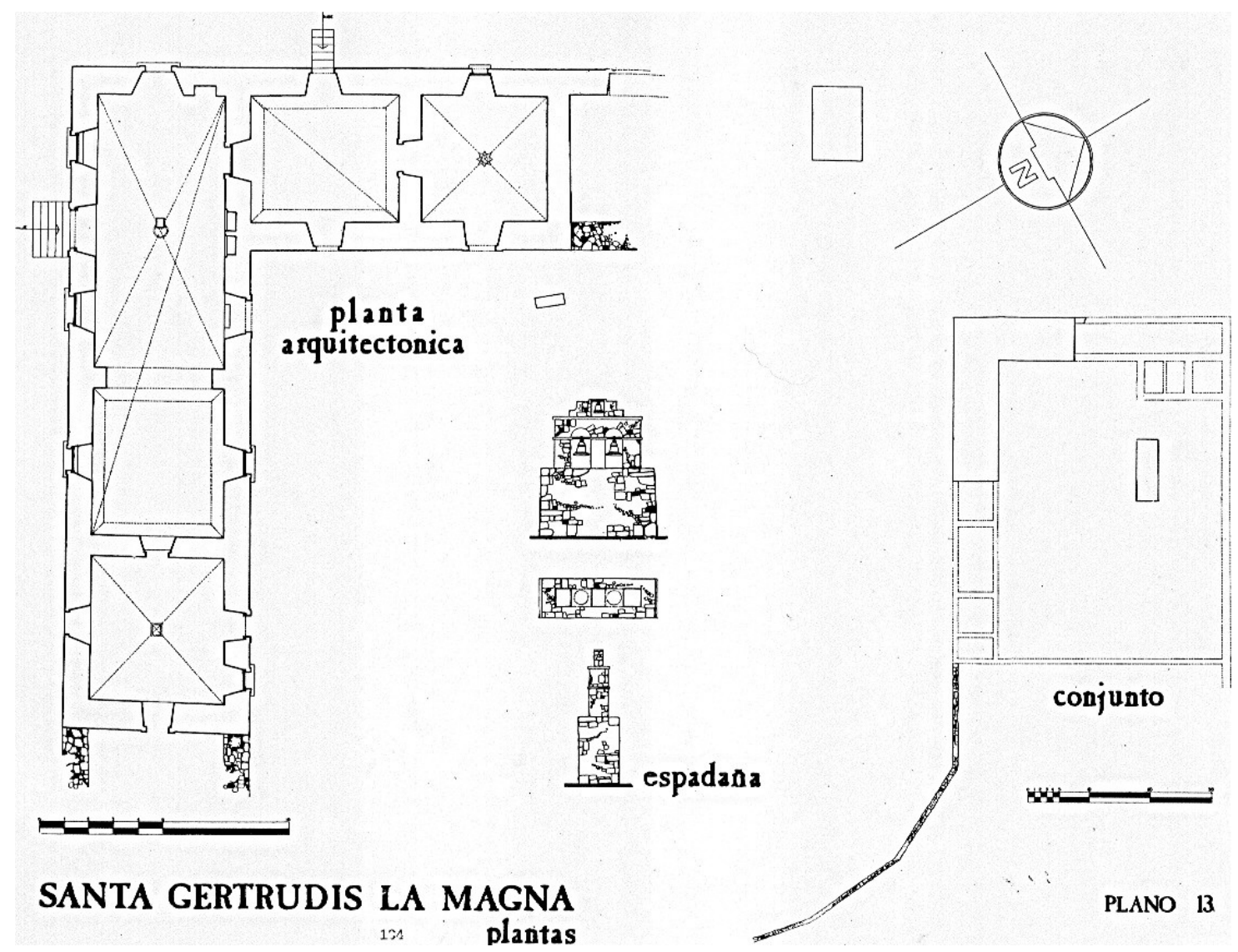

Fig. 1. Diagrama que muestra las estructuras de la misión de Santa Gertrudis. (Tomado de José Luis Aguilar Marco, et al., Misiones en la península de Baja California [México, D.F., 1991].)

La construcción de la misión Rosario tuvo por lo menos dos etapas. Las primeras edificaciones, completadas a comienzos de 1755, fueron construidas con madera, que era abundante en Texas, al contrario del Desierto Central de Baja California. Un documento de enero de 1755 señala que la misión consistía en "una decente iglesia 
[hecha de madera], vivienda para el ministro y otras casas y oficinas necesarias." ${ }^{34}$ Una década después, en 1767, un informe describía las edificaciones de la misión en los siguientes términos:

Los edificios de la misión y los cuartos de vivienda de los sacerdotes, al igual que aquellas de los indios y soldados, son buenas estructuras y suficientemente grandes. Una muy buena palizada [estacas de madera clavadas en el piso], hecha de estacas gruesas y fuertes, protege la misión de cualquier ataque. La iglesia, un edificio muy bueno y sólido, está blancamente lavado y hermosamente decorado. En el interior está reforzada con arcilla, y tiene un hermoso tejado con fuertes vigas y tablitas de madera utilizadas como tejas. ${ }^{35}$

Las estructuras que formaban la misión de Rosario en 1767, trece años después de su establecimiento, todavía eran de madera. En Rosario, la transición a materiales más resistentes ocurrió después.

Los franciscanos situados en Rosario experimentaron problemas con los neófitos y abandonaron la misión durante casi una década (esto será analizado detalladamente más adelante). En una descripción de la misión, fechada en 1789, se escribió el siguiente comentario: "Aunque con respecto a la misión, no costará mucho terminar su reconstrucción, ya que la pared que rodea al convento y a la sacristía está en buen estado, así como otros dos cuartos. Sólo la iglesia se ha caído." 36 Un documento de 1790 suministró una apreciación más detallada de las condiciones de la misión:

Con respecto a la fabricación o construcción de la misión, la pequeña pared que la rodea está muy deteriorada porque es muy vieja y no se le ha hecho un debido mantenimiento. La casa en la que vive el Padre Ministro no tiene tejado, aunque sus paredes permanecen fuertes y sin el menor cambio. En cuanto a la iglesia, ni siquiera hay ruinas. El actual sacerdote usaba una choza con techo de paja [y es] tan pequeña que a duras penas caben el altar y el confesionario. La actual vivienda del padre es una pequeña casa con un techo de césped [que es] muy incómoda como [la vivienda] de los soldados y algunos criados que los atienden. ${ }^{37}$

\footnotetext{
${ }^{34}$ Citado en Kathleen Gilmore, Mission Rosario: Archeological Investigation (Austin: State of Texas Department of Parks, 1974), 1:18.

${ }^{35}$ Forrestal, "Solís Diary."

${ }^{36}$ Citado en Gilmore, Mission Rosario, 2:8.

${ }^{37}$ Citado en Ibid., 2:9.
} 
Entre 1790 y 1791, el franciscano Jaudenes dirigió la restauración de la misión Rosario, y organizó la reconstrucción de la iglesia el 9 de noviembre de $1791 .^{38}$ En la reconstrucción se utilizó como material de construcción piedra en vez de madera, y las ruinas del sitio de la misión datan del periodo de 1790-1791. El franciscano Huerta reportó en 1804 que "una parte de la casa y una sección de la iglesia en el espacio de la puerta [se han] caído [debido a] una lluvia que cayó el 20 y 24 de este mes [agosto]. Varias secciones de la pared [que rodean la misión] también se cayeron [durante la lluvia]. ${ }^{39}$ En 1805, Huerta se trasladó con los neófitos restantes a la misión Refugio, que estaba más cerca de la costa, y en 1807 las misiones Rosario y Refugio fueron formalmente fusionadas. ${ }^{40}$ La misión abandonada terminó en ruinas.

La construcción en Rosario de edificios en piedra pudo haber empezado a fines de la década de 1770, pero es posible que no estuviera completa cuando ocurrió una gran revuelta indígena, que llevó a abandonar la misión en 1779. Los informes de la misión en 1790, sugieren que algunas estructuras estaban en buen estado, pero la iglesia, según esos mismos informes, estaba en malas condiciones. El proyecto de construcción de 1790-1791 probablemente incluía la terminación o reparación de la iglesia, y quizás el embellecimiento de otras estructuras. ${ }^{41}$ Cuando se finalizó en 1791, la misión Rosario fue construida con una pared que rodeaba, y a la vez protegía, las estructuras principales, lo cual era común en las misiones construidas en Texas, ya que eran vulnerables a ataques por parte de los Apaches y Comanches. Adentro de las paredes estaban la iglesia, las residencias para los misioneros, y otras estructuras que pudieron haber incluido talleres y/o almacenes o graneros. Las viviendas para los indígenas, aparentemente, se encontraban también adentro de las paredes, como fue señalado en el mencionado informe de 1767.

\section{La economía de las misiones}

La principal meta de los jesuitas en Baja California era cubrir al máximo los costos de las misiones, y en segunda instancia, proveer un nivel aceptable de vida, tanto para ellos como para los neófitos. El cubrimiento de los costos de las misiones sería lo que luego les permitiría volver a Baja California, gracias al permiso de la corona, a establecer más misiones; los jesuitas pudieron cubrir los costos, ya que solicitaron fondos de fuentes

\footnotetext{
${ }^{38}$ Ibid., 2:9-10.

${ }^{39}$ Ibid., 2:11.

${ }^{40}$ Ibid., 2:11.

${ }^{41}$ Ibid., 2:33-4.
} 
privadas, y mediante la recolección de limosna en ciudades y pueblos de México, siempre ayudados por las provisiones que les enviaban de las misiones de Tarahumara, Sinaloa y Sonora. ${ }^{42}$

El primer requisito para establecer una misión en Baja California era una dotación, casi siempre de 10,000 pesos, invertidos en propiedades urbanas o bienes raíces urbanos, que produjeran un ingreso. La meta era recoger anualmente alrededor de 500 pesos de estas inversiones. ${ }^{43}$ En muchos casos, jesuitas adinerados donaban los fondos necesarios para la dotación. Por ejemplo, Juan Bautista Luyando, S.J., donó 10,000 pesos para financiar la misión de San Ignacio, y luego fue su primer misionero. ${ }^{44}$ Luego de la expulsión de los jesuitas en 1768, la corona tomó posesión de los fondos y los utilizó para financiar la colonización de las Californias. Luego se conoció como el Fondo Piadoso de las Californias, y se convirtió en el motivo de un conflicto legal entre México y los Estados Unidos durante casi todo el siglo XIX. Los misioneros jesuitas utilizaban el dinero de la dotación para cubrir los costos de las provisiones compradas para las misiones, y tenían que mantener un claro informe de sus gastos, que debía ser presentado a los inspectores jesuitas (visitadores generales) durante sus periódicas visitas a las misiones.

Entre 1743 y 1744, Juan Antonio Balthasar, S.J., visitó las misiones de Baja California. $\mathrm{Su}$ informe de la misión de Guadalupe muestra las diferentes maneras mediante las cuales los jesuitas obtenían las provisiones necesarias para que la misión funcionara. Entre 1742 y 1744, el misionero José Gasteirger, S.J., había obtenido, a través de la tesorería de Loreto, provisiones equivalentes a 1,760 pesos, ya que utilizó los fondos de la dotación. También Gasteirger había aplicado el intercambio para obtener provisiones adicionales, que equivalían a un total de 1,440 pesos. El jesuita le había vendido a la misión de San Ignacio productos agrícolas por un monto de 266 pesos, que aún debían ser cobrados. ${ }^{45}$ Los mercados locales o regionales de Baja California jamás llegaron a ser más que un sistema de intercambio local.

\footnotetext{
${ }^{42}$ Joseph Rodero, en un informe de 1736, sintetizó las finanzas de las misiones de Baja California, y particularmente las fuentes de donde conseguían fondos (traducido en Burrus, Jesuit Relations, 198). Entre 1697 y 1720, las donaciones hechas a las misiones equivalían a 105,000 pesos, un poco menos de la quinta parte del total de los fondos que eran enviados a las misiones de la Península. Las limosnas de las ciudades y pueblos mexicanos sumaban en total 115,500 pesos.

${ }^{43}$ Ibid., 198.

${ }^{44}$ Ibid., 198.

${ }^{45}$ Ibid., 213.
} 
Con la excepción de San Ignacio, las misiones del Desierto Central tenían un limitado potencial agrícola, y en los primeros años las misiones jamás produjeron suficiente grano para poder alimentar a la población neófita. Los misioneros dirigieron la construcción de sistemas de riego con represas que recogían el agua disponible para poder cultivar las tierras, pero estos sistemas de riego resultaron ser vulnerables a las inesperadas inundaciones que destruían o dañaban la represa y los diques, llenando los campos de arena y grava. ${ }^{46}$ Los cultivos básicos eran de trigo y maíz, a veces complementados por cultivos de cebada. Los cultivos especializados incluían algodón y uvas para la fabricación de vino y brandy. Como lo demuestran las tablas 2 a 6 , la producción de los cultivos en las misiones era baja, y fluctuaba de año en año dependiendo de factores externos como la disponibilidad de agua para el riego.

Otro elemento importante de la economía era la ganadería. Las misiones tenían caballos, ganado vacuno, ovejas y cabras (ver tablas 2 a 6). Estos rebaños proveían carne para complementar la dieta de aquellos neófitos alimentados por los misioneros, y también proveían materia prima para la elaboración de productos de cuero, sebo para jabones y velas, y lana para la ropa. Los rebaños de las misiones del Desierto Central jamás superaron el número que tenían las misiones al norte de California. El gran obstáculo para mantener un alto número de animales en las misiones de la Península era encontrar suficiente pasto. Los misioneros también reportaron pérdidas ocasionadas por depredadores salvajes, como los pumas.

La economía de la misión Rosario era similar a la de aquellas establecidas en el Desierto Central. La corona suministraba una dotación para cada uno de los establecimientos franciscanos en Texas, y cada año le otorgaba fondos al colegio apostólico que administraba las misiones. El representante secular del colegio apostólico utilizaba los fondos para comprar las provisiones pedidas por los misioneros, que debían ser enviadas

\footnotetext{
${ }^{46}$ Para la utilización del sistema de riego, consultar, por ejemplo, Sebastián de Sistiaga, S.J., San Ignacio, 1744, Jesuit Relations, 140. Acerca de San Ignacio, Juan Antonio Balthasar, S.J., señaló que: "La misión recoge grandes cosechas de trigo, maíz y uvas" (Ibid., 214). En 1771, Francisco Palou, O.M.F., escribió que: "La misión está situada en un elevado sitio, desde el cual se ve el extenso valle con su arroyo que tiene suficiente agua, que es recogida por medio de una represa y llevada mediante zanjas hasta la misión, donde se mantiene en una gran reserva fabricada por los albañiles. Tiene suficiente tierra; a pesar de que en 1770 la inundación provocada por el arroyo se llevó la tierra, cuando destruyó la represa, dejando tan solo un campo lleno de arena, todavía hay suficiente tierra." Citado en Engelhardt, Missions and Missionaries, 482.
} 
a Texas. ${ }^{47}$ El ejército en Texas no dependía de las misiones de la costa del golfo para sus provisiones, así que la agricultura y la reproducción de los rebaños cubría principalmente las necesidades locales. Existe muy poca información acerca de la producción agrícola, a pesar de que es sabido que los franciscanos intentaron desarrollar por lo menos el cultivo del grano. Un inconveniente para la agricultura pudo haber sido la inestabilidad de la mano de obra, dado los patrones migratorios de los indígenas, discutidos anteriormente. Los franciscanos intentaron poner a trabajar a los indígenas, y Gaspar de Solís, O.F.M, reportó la utilización de castigos corporales para disciplinar a los nativos. ${ }^{48}$ Otro factor que limitaba el desarrollo económico era el clima, especialmente las lluvias.

Tabla 2

Cantidad de animales y producción de grano (en fanegas) reportada en la Misión de Guadalupe

\begin{tabular}{|c|c|c|c|c|c|c|c|}
\hline Año & Ganado vacuno & Ovejas & Cabras & Caballos & Trigo & Maíz & Cebada \\
\hline 1755 & 1,500 & $1,870 *$ & & 130 & & & \\
\hline 1761 & 4,000 & & & 319 & & & \\
\hline 1771 & 212 & 947 & 383 & 132 & & & \\
\hline 1773 & 120 & 396 & 500 & 127 & & & \\
\hline 1774 & 141 & 690 & 319 & 119 & 200 & & \\
\hline 1775 & 252 & 604 & 614 & 117 & 205 & & \\
\hline 1776 & 261 & 470 & 658 & 103 & 146 & 58 & \\
\hline 1780 & 272 & 480 & 415 & 94 & & & \\
\hline 1782 & 243 & 800 & 600 & 109 & & & \\
\hline 1784 & 352 & 583 & 343 & 122 & & & \\
\hline 1785 & 460 & $833^{*}$ & & 136 & & & \\
\hline 1786 & 517 & 700 & & 113 & & & \\
\hline 1787 & 360 & 500 & 269 & 113 & 160 & 100 & \\
\hline 1793 & 500 & 600 & 48 & 55 & & & \\
\hline 1794 & 160 & 361 & 125 & 56 & & & \\
\hline
\end{tabular}

* Incluye cabras.

\footnotetext{
${ }^{47}$ Robert H. Jackson, From Savages to Subjects: Missions in the History of the American Southwest (Armonk: M.E. Sharpe, 2000), 10-23.

${ }^{48}$ Forrestal, "Solís Diary."
} 
Fuentes: Aschmann, Central Desert of Baja California, 212; Urera, Nuevo estado de las misiones, W. B. Stephens Collection; y "Baja California Mission Statistics," University of California, Berkeley, The Bancroft Library.

Tabla 3

Cantidad de animales y producción de grano (en fanegas) reportada en la Misión de San Ignacio, 1755-1805.

\begin{tabular}{|c|c|c|c|c|c|c|c|}
\hline Año & Ganado vacuno & Ovejas & Cabras & Caballos & Trigo & Maíz & Cebada \\
\hline 1728 & & & & & 100 & & \\
\hline 1729 & & & & & 450 & & \\
\hline 1755 & 1,150 & 1755 & 1,250 & 100 & 500 & 500 & \\
\hline 1761 & 1,500 & $1,000^{*}$ & & & & & \\
\hline 1771 & 87 & 722 & 43 & 112 & & & \\
\hline 1773 & 125 & 558 & 194 & 127 & & & \\
\hline 1774 & 215 & 400 & 160 & 118 & 60 & & 40 \\
\hline 1775 & 234 & 500 & 192 & 104 & 65 & 223 & 30 \\
\hline 1776 & 300 & 534 & 220 & 121 & 470 & 160 & \\
\hline 1780 & 420 & 700 & 300 & 23 & & & \\
\hline 1782 & 500 & 600 & 300 & 85 & & & \\
\hline 1784 & & 433 & 226 & 93 & 600 & 160 & \\
\hline 1785 & 400 & & & 71 & 550 & 200 & \\
\hline 1786 & 380 & 400 & 250 & 82 & 800 & 200 & \\
\hline 1787 & 472 & 555 & 217 & 107 & 900 & 230 & \\
\hline 1788 & 360 & 630 & 190 & 103 & 600 & 237 & 15 \\
\hline 1793 & 300 & 900 & 150 & 136 & 680 & & \\
\hline 1794 & 340 & 800 & 200 & 121 & 600 & 34 & 3 \\
\hline 1795 & 324 & 800 & 100 & 140 & 80 & 80 & \\
\hline 1796 & 400 & 895 & 200 & 79 & 500 & 10 & \\
\hline 1797 & 488 & 875 & 297 & 132 & 451 & 100 & \\
\hline 1798 & 480 & 816 & 230 & 120 & 800 & 150 & \\
\hline 1799 & 478 & 750 & 250 & 190 & 500 & 20 & \\
\hline 1800 & 516 & 642 & 282 & 190 & 500 & 50 & \\
\hline 1801 & 600 & $747^{*}$ & & 170 & 400 & 150 & \\
\hline 1803 & 650 & 520 & 236 & 104 & 350 & 90 & \\
\hline 1805 & 550 & 300 & 200 & 65 & 200 & 40 & \\
\hline
\end{tabular}


Fuentes: Aschmann, Central Desert of Baja California, 214-5; Urera, Nuevo estado de las misiones, W. B. Stephens Collection; y "Baja California Mission Statistics," University of California, Berkeley, The Bancroft Library. 
Tabla 4

Cantidad de animales y producción de grano (en fanegas) reportado en la Misión de Santa Gertrudis, 1755-1805.

\begin{tabular}{|c|c|c|c|c|c|c|c|}
\hline Año & Ganado vacuno & Ovejas & Cabras & Caballos & Trigo & Maíz & Cebada \\
\hline 1755 & 440 & & & 45 & 151 & 28 & \\
\hline 1771 & 113 & 140 & 470 & 142 & 180 & & 20 \\
\hline 1773 & 196 & 210 & 320 & 118 & 138 & & 50 \\
\hline 1774 & 169 & 490 & 169 & 109 & 85 & 93 & 15 \\
\hline 1775 & 330 & $706^{*}$ & & & 340 & & 20 \\
\hline 1776 & 288 & 464 & 548 & 143 & 250 & 118 & \\
\hline 1780 & 280 & 300 & 470 & 158 & & & \\
\hline 1782 & 272 & 177 & 600 & 35 & 200 & 78 & \\
\hline 1784 & 236 & 223 & 735 & 55 & 147 & 32 & \\
\hline 1785 & 321 & & & 88 & 159 & 12 & \\
\hline 1786 & 236 & 360 & 400 & 68 & & & \\
\hline 1787 & 329 & 408 & 350 & 140 & & & \\
\hline 1788 & 260 & & & 61 & & & \\
\hline 1793 & 300 & 700 & 200 & 71 & 200 & & \\
\hline 1794 & 230 & 800 & 144 & 95 & 150 & 11 & \\
\hline 1795 & 120 & 1,060 & 220 & 86 & 300 & 60 & 4 \\
\hline 1796 & 60 & 1,250 & 236 & 110 & 280 & 50 & \\
\hline 1797 & 60 & 1,150 & 300 & 139 & 160 & 8 & 10 \\
\hline 1798 & 13 & 1,146 & 290 & 70 & 180 & 14 & 20 \\
\hline 1799 & 74 & 2,100 & 600 & 94 & 150 & 50 & 40 \\
\hline 1800 & 80 & 2,220 & 550 & 60 & 100 & 14 & 6 \\
\hline 1801 & 70 & 2,125 & 635 & 70 & 150 & & 15 \\
\hline 1803 & 76 & 2,020 & 543 & 62 & 60 & 15 & \\
\hline 1805 & 96 & 2,227 & 402 & 32 & 35 & 26 & \\
\hline
\end{tabular}

Fuentes: Aschmann, Central Desert of Baja California, 220; Urera, Nuevo estado de las misiones, W. B. Stephens Collection; y "Baja California Mission Statistics,” University of California, Berkeley, The Bancroft Library. 
Tabla 5

Cantidad de animales y producción de grano (en fanegas) reportado en la Misión San Francisco de Borja, 1771-1805.

\begin{tabular}{|c|c|c|c|c|c|c|c|}
\hline Año & Ganado & Ovejas & Cabras & Caballos & Trigo & Maíz & Cebada \\
\hline 1771 & 500 & 1,700 & 930 & 219 & 300 & & 189 \\
\hline 1773 & 648 & 2,343 & 1,003 & 305 & 503 & 9 & 22 \\
\hline 1774 & 536 & 2,328 & 968 & 178 & & & \\
\hline 1775 & 462 & 1,551 & 459 & 229 & 460 & & \\
\hline 1776 & 251 & 1,245 & 724 & 142 & 500 & 100 & 10 \\
\hline 1780 & 393 & 1,134 & 843 & 221 & & & \\
\hline 1782 & 366 & 1,079 & 614 & 127 & 280 & 60 & 1 \\
\hline 1783 & 150 & & & & & & \\
\hline 1784 & 320 & 1,600 & 1,000 & 120 & 300 & 70 & \\
\hline 1785 & 330 & 1,900 & 1,000 & 120 & 300 & 80 & \\
\hline 1786 & 320 & 2,200 & 1,100 & 80 & 300 & 80 & \\
\hline 1787 & 400 & 3,000 & & 125 & 250 & 80 & \\
\hline 1788 & 400 & 2,000 & 1,000 & 100 & 14 & 70 & \\
\hline 1793 & 123 & 1,192 & 217 & 69 & 110 & & \\
\hline 1794 & 193 & 608 & 236 & 62 & 200 & 80 & 19 \\
\hline 1795 & 216 & 750 & 210 & 76 & 250 & 90 & 30 \\
\hline 1796 & 333 & 700 & 300 & 100 & 300 & 100 & 80 \\
\hline 1797 & 284 & 591 & 258 & 110 & 300 & 90 & 100 \\
\hline 1798 & 421 & 663 & 312 & 70 & 200 & 100 & 70 \\
\hline 1799 & 490 & 800 & 500 & 125 & 280 & 120 & 180 \\
\hline 1800 & 231 & 600 & 400 & 84 & 180 & 80 & 60 \\
\hline 1801 & 500 & 600 & 400 & 85 & 180 & 130 & 50 \\
\hline 1803 & 700 & 1,200 & 900 & 133 & 100 & 90 & 12 \\
\hline 1805 & 500 & 400 & 300 & 28 & 110 & 90 & 6 \\
\hline
\end{tabular}

Fuentes: Aschmann, Central Desert of Baja California, 222-3; Annual Reports, 1795-1798, Archivo General de la Nación, México, D.F.; y "Baja California Mission Statistics," University of California, Berkeley, The Bancroft Library. 
Tabla 6

Cantidad de animales y producción de grano (en fanegas) reportada en la Misión San Fernando, 1771-1805

\begin{tabular}{|c|c|c|c|c|c|c|}
\hline Año & Ganado & Ovejas & Caballos & Trigo & Maíz & Cebada \\
\hline 1771 & 49 & 40 & 12 & 200 & & \\
\hline \multicolumn{7}{|l|}{1772} \\
\hline 1773 & 75 & 71 & 12 & 107 & & 26 \\
\hline 1774 & 75 & 55 & 11 & & & \\
\hline 1775 & 79 & 98 & 24 & 100 & & \\
\hline 1776 & 107 & 186 & 30 & 200 & & 300 \\
\hline \multicolumn{7}{|l|}{1777} \\
\hline \multicolumn{7}{|l|}{1778} \\
\hline \multicolumn{7}{|l|}{1779} \\
\hline 1780 & 114 & 227 & 34 & & & \\
\hline \multicolumn{7}{|l|}{1781} \\
\hline 1782 & 110 & 178 & 12 & 338 & 410 & 107 \\
\hline 1783 & 120 & & & & & \\
\hline 1784 & 152 & 310 & 12 & 700 & 260 & \\
\hline 1785 & 113 & 287 & 12 & 950 & 140 & \\
\hline 1786 & 107 & 279 & 10 & 940 & 120 & \\
\hline 1787 & 88 & 130 & 12 & 400 & 130 & \\
\hline 1788 & 38 & 189 & 10 & 29 & 70 & \\
\hline \multicolumn{7}{|l|}{1789} \\
\hline \multicolumn{7}{|l|}{1790} \\
\hline \multicolumn{7}{|l|}{1791} \\
\hline \multicolumn{7}{|l|}{1792} \\
\hline 1793 & 113 & 202 & 31 & 767 & & \\
\hline 1794 & 77 & 100 & 28 & 515 & 104 & \\
\hline 1795 & 100 & 60 & 28 & 500 & 200 & \\
\hline 1796 & 101 & 150 & 12 & 493 & 100 & \\
\hline
\end{tabular}




\begin{tabular}{rrrccrr}
\hline Año & Ganado & Ovejas & Caballos & Trigo & Má́z & Cebada \\
\hline 1797 & 67 & 140 & 38 & 300 & 130 & \\
1798 & 70 & & & 800 & 150 & 30 \\
1799 & 60 & 128 & & 380 & 1 & 6 \\
1800 & 110 & 103 & & 450 & 80 & 130 \\
1801 & 170 & 60 & 54 & 200 & 60 & 12 \\
1802 & 160 & 54 & 58 & 500 & 40 & 12 \\
1803 & & & & & & \\
1804 & 100 & 120 & 39 & 700 & 90 & 21 \\
1805 & & & & & & \\
\hline
\end{tabular}

Fuentes: Annual Reports, Archivo General de la Nación, México, D.F.; Aschmann, Central Desert of Baja California, 228-9.

Solís escribió la primera descripción detallada de la misión Rosario. Notó que: “esta misión ha sembrado los campos, pero depende de las lluvias, ya que es imposible extraer agua del río, considerando los grandes bancos, y no hay agua en el sitio donde se fundó la misión en 1754." ${ }^{49}$ Dada la inestabilidad de la agricultura, los franciscanos situados en Rosario pudieron haber incrementado la ganadería. Solís contó el número de animales en la misión Rosario: 5,000 cabezas de ganado, 200 vacas, 700 ovejas, dos hatos de caballos, 40 caballos amansados y 30 mulas amansadas. ${ }^{50}$ Los rebaños de ganado, que se encontraban en un rancho establecido en las tierras tupidas retiradas del Río San Antonio, pudieron haber sido de por lo menos 30,000 animales a comienzos de la década de $1780 .^{51}$ La multiplicación de los animales de las misiones resultó problemática para los Karankawas, ya que el ganado y las ovejas desplazaron a animales tradicionales de caza, como los bisontes y ciervos, y destruyeron las fuentes de comida que ofrecían las plantas silvestres. Oficiales españoles en Texas expresaron una gran preocupación por los indígenas que vivían fuera de las misiones, ya que éstos pudieron haber atacado a los rebaños. ${ }^{52}$

\section{Patrones demográficos}

\footnotetext{
${ }^{49}$ Ibid.

${ }^{50}$ Ibid.

${ }^{51}$ Ricklis, Karankawa Indians of Texas, 70-1.

${ }^{52}$ Ibid., 148.
} 
He estudiado en otra parte los patrones demográficos de los indígenas en las misiones. ${ }^{53}$ Los jesuitas bautizaron cientos de nativos en el Desierto Central, pero, como lo señalé anteriormente, muchos de ellos continuaron viviendo su vida tradicional durante décadas. No obstante, hubo un cambio significativo: la introducción masiva de nuevas y altamente contagiosas enfermedades, como la viruela, el sarampión, y otras que eran crónicas y con el tiempo debilitantes, como la sífilis. Las epidemias periódicas fueron una importante causa de mortalidad entre los neófitos, y la sífilis debilitaba a los sobrevivientes. Las nuevas enfermedades, especialmente la disentería, se veían periódicamente en las misiones de la Península. Luego de tres o cuatro generaciones, la población indígena se enfrentaba a una posible extinción biológica.

Cuando había suficientes portadores potenciales que mantuvieran la cadena de infección, la viruela y el sarampión atacaban a la población indígena por lo menos una vez por generación. Es más, los catorce años entre 1768 y 1782, luego de la expulsión de los jesuitas y los proyectos para colonizar California, fueron testigos de unas de las más devastadoras epidemias. El contacto entre los habitantes de la península y aquellos que habitaban tierras alejadas del mar se incrementó, por lo que la posibilidad de que la infección se propagara fue mayor. Un buen ejemplo de esto es la viruela que atacó a la población entre los años 1781 y 1782. Un grupo de familias viajando hacia California se detuvo en Loreto, luego de haber pasado por Sinaloa, y un miembro del grupo de los colonos tenía viruela. La viruela se empezó a regar mientras que las familias viajaban hacia el norte, rumbo a California. Cien años después, cientos de neófitos habían muerto por la enfermedad. ${ }^{54}$ Tres epidemias devastaron la población de las misiones: 1769 , 1772-1773 y 1781-1782. En el caso de Santa Gertrudis, el 79 por ciento del total de las muertes entre 1764 y 1881 (cuando Jorge Retz, S.J., bautizó a los últimos no cristianos de la región) se debió a estas epidemias. En San Francisco de Borja, el 51 por ciento de las muertes de la población neófita entre 1769 y 1816 se debió a las epidemias de 1769 y la de $1772-1773 .^{55}$

Las cifras se redujeron luego de que los misioneros bautizaron a la población indígena en las regiones de las misiones (ver tabla 7). Si bien las epidemias reducían la población, ya el nuevo orden colonial se había visto como perjudicial y poco saludable para los

\footnotetext{
${ }^{53}$ Jackson, Indian Population Decline.

${ }^{54}$ Robert H. Jackson, "Epidemic Disease and Population Decline in the Baja California Missions, $1697-$ 1834,” Southern California Quarterly 63, no. 4 (1984): 91-112.

55 Jackson, "Demographic Patterns," 91-112.
} 
nativos. La tasa de mortalidad de los niños era alta, y el promedio de vida disminuyó especialmente durante los años de las epidemias (ver tabla 8). Cuando los misioneros intentaron erradicar las prácticas chamánicas, destruyeron siglos de conocimiento acerca de los cuidados prenatales y de educación infantil, de tal manera que las mujeres recibían un cuidado insuficiente. A medida que las enfermedades venéreas se esparcían, las mujeres se volvieron infértiles y más susceptibles a otras enfermedades. Al final del siglo XVIII ya se percibía un desequilibrio entre los géneros y la edad en la población indígena: había más hombres que mujeres y pocos niños. Llegó el punto en el que la población indígena no se podía multiplicar. En las décadas de 1820 y 1830, la que alguna vez había sido una numerosa población indígena se había reducido a menos de cien personas viviendo en las misiones.

Tabla 7

Población de las misiones del Desierto Central de Baja California.

\begin{tabular}{|c|c|c|c|c|c|c|}
\hline Año & Guadalupe & San Ignacio & Santa Gertrudis & San Borja & Santa María & San Fernando \\
\hline 1723 & 2,000 & & & & & \\
\hline 1726 & 1,701 & & & & & \\
\hline 1730 & & 1,249 & & & & \\
\hline 1744 & 701 & 1,196 & & & & \\
\hline 1752 & & 1,147 & & & & \\
\hline 1755 & 472 & 1,012 & 1,586 & & & \\
\hline 1761 & 524 & 800 & 1,735 & & & \\
\hline 1762 & 535 & 838 & 1,730 & 498 & & \\
\hline 1767 & 530 & & & 1,492 & 300 & \\
\hline 1768 & 544 & & & 1,640 & 509 & \\
\hline 1770 & 176 & 572 & 1,244 & 1,538 & 411 & 349 \\
\hline 1771 & 140 & 558 & 1,138 & 1,479 & 523 & 368 \\
\hline 1773 & 169 & 314 & 800 & 1,000 & 317 & 293 \\
\hline 1774 & 176 & 305 & 798 & 978 & 485 & 256 \\
\hline 1775 & 170 & 300 & 812 & 958 & & 1,406 \\
\hline Año & Guadalupe & San Ignacio & Santa Gertrudis & San Borja & Santa María & San Fernando \\
\hline
\end{tabular}




\begin{tabular}{|c|c|c|c|c|c|}
\hline 1776 & 179 & 282 & 769 & 833 & 1,216 \\
\hline 1782 & 105 & 241 & 317 & 657 & 642 \\
\hline 1786 & 86 & 279 & 284 & 697 & 559 \\
\hline 1787 & 106 & 273 & 297 & 695 & 567 \\
\hline 1790 & 84 & 216 & 241 & 614 & 479 \\
\hline 1791 & 73 & 210 & 244 & 623 & 506 \\
\hline 1793 & 74 & 178 & 237 & 554 & 506 \\
\hline 1794 & 74 & 190 & 234 & 539 & 525 \\
\hline 1795 & & 168 & 217 & 500 & 550 \\
\hline 1796 & & 152 & 224 & 452 & 452 \\
\hline 1797 & & 139 & 218 & 450 & 450 \\
\hline 1798 & & 133 & 226 & 443 & 425 \\
\hline 1799 & & 137 & 203 & 351 & 476 \\
\hline 1800 & & 130 & 203 & 400 & 363 \\
\hline 1801 & & 120 & 208 & 395 & 313 \\
\hline 1802 & & 113 & 198 & 359 & 295 \\
\hline 1803 & & 125 & 171 & 344 & 263 \\
\hline 1804 & & 113 & 198 & 359 & 193 \\
\hline 1806 & & 102 & 137 & 270 & 201 \\
\hline 1808 & & 81 & 137 & 192 & 155 \\
\hline 1823 & & & 44 & 46 & \\
\hline 1829 & & & & & 19 \\
\hline 1836 & & & 40 & 40 & 15 \\
\hline
\end{tabular}

Fuentes: Aschmann, Central Desert of Baja California, 182-3, 253; Jackson, Indian Population Decline, 167-8. 
Tabla 8

Estadísticas demográficas de la Misión Santa Gertrudis, 1757-1811.

\begin{tabular}{lcccc}
\hline Quinquenio & $\begin{array}{c}\text { Población } \\
\text { Estimada }\end{array}$ & $\begin{array}{c}\text { Tasa bruta de } \\
\text { nacimientos }\end{array}$ & $\begin{array}{c}\text { Tasa bruta de } \\
\text { defunciones }\end{array}$ & $\begin{array}{c}\text { Expectativa promedio } \\
\text { de vida }\end{array}$ \\
\hline $1757-1761$ & 1,432 & 42 & 63 & 9.4 \\
$1762-1766$ & 1,642 & 42 & 63 & 11.5 \\
$1767-1771$ & 1,313 & 52 & 74 & 10.2 \\
$1772-1776$ & 798 & 43 & 106 & 2.8 \\
$1777-1781$ & 555 & 52 & 119 & 1.6 \\
$1782-1786$ & 383 & 40 & 121 & 1.4 \\
$1787-1791$ & 280 & 40 & 46 & 20.8 \\
$1792-1796$ & 234 & 41 & 53 & 20.1 \\
$1797-1801$ & 203 & 41 & 45 & 25.8 \\
$1802-1806$ & 198 & 44 & 106 & 5.4 \\
$1807-1811$ & 124 & 44 & 84 & 8.3 \\
\hline
\end{tabular}

Fuentes: Jackson, Indian Population Decline, 77.

Debido a la imposibilidad de los franciscanos por inducir a los Karankawas a vivir de manera permanente en las misiones, los patrones demográficos en la misión Rosario eran más complejos. La única información que tenemos acerca de los patrones demográficos de la misión Rosario son los censos que han sobrevivido hasta nuestros días (ver tabla 9). Solís compendió el número de bautizos y entierros ocurridos entre 1754 y 1768: un total de 137 bautizos entre 1754 y 1758, otros 63 entre 1758 y 1768, y 110 entierros entre los años 1754 y $1768 .^{56}$ Estos números sugieren una alta tasa de mortalidad. Censos realizados en la década de 1790 contienen un esbozo de la proporción de género y de edad en las misiones. ${ }^{57}$ Los niños menores de nueve años, llamados párvulos por los españoles, eran entre un cuarto y un tercio de la población de la misión Rosario. La proporción de sexos estuvo más o menos balanceada durante muchos años. La única excepción ocurrió entre los años 1796 y 1797, cuando aparentemente había menos hombres, ya que probablemente habían dejado a las mujeres

\footnotetext{
${ }^{56}$ Ibid., 173.

${ }^{57}$ Kathleen Gilmore, “The Indians of Mission Rosario," en The Scope of Historical Archaeology: Essays in Honor of John L. Cotter, ed. David Orr y Daniel Crozier (Filadelfia: Temple University Press, 1984), 163-91.
} 
y a los niños en la misión mientras estaban de caza o realizando cualquier otra actividad. Los censos informan el número de niños por familia, y los Karankawas que vivían en Rosario tendían a tener pequeñas familias con tan solo uno o dos pequeños. Esto puede ser interpretado como la manifestación de un patrón cultural de tener familias más pequeñas, y/o también un efecto del alto índice de mortalidad de los infantes.

Tabla 9

Población de la Misión Rosario, 1754-1805.

\begin{tabular}{lrlr}
\hline Año/Fecha & Población & Año/Fecha & Población \\
1754 & 500 & Agosto 1793 & 139 \\
1758 & 400 & Octubre 1795 & 107 \\
1768 & 101 & Octubre 1796 & 148 \\
Mayo 1790 & 51 & Diciembre 1796 & 97 \\
Diciembre 1790 & 67 & Junio 1797 & 254 \\
Marzo 1791 & 85 & Diciembre 1798 & 70 \\
Julio 1791 & 57 & 1802 & 63 \\
Noviembre 1791 & 114 & 1804 & 61 \\
Junio 1792 & 83 & 1805 & 62 \\
\hline
\end{tabular}

Fuente: Jackson, “Congregation and Population Change,” 163-83.

Los franciscanos no estuvieron cerca de congregar toda la población de Karankawas, y muchos grupos continuaron resistiendo la presencia española. En 1793, los franciscanos establecieron la misión Refugio más cerca del territorio de los Karankawas, y los neófitos de Rosario optaron por trasladarse a la nueva misión en 1797. En 1805, Fr. Huerta se trasladó a Refugio con los indígenas que quedaban, y en 1807 las dos misiones fueron formalmente fusionadas. ${ }^{58}$ Los Karankawas se establecieron con menor resistencia en la misión Refugio, situada en su territorio tradicional, en $1793 .{ }^{59}$

\section{Resistencia y adaptación}

\footnotetext{
${ }^{58}$ Gilmore, Mission Rosario, 2:11.

${ }^{59}$ Ricklis, Karankawa Indians of Texas, 153.
} 
Hubo relativamente poca resistencia a las misiones en el Desierto Central de Baja California. Los nativos que estaban situados en el desierto vivían en pequeños grupos, y no tenían experiencia alguna con una organización política más avanzada. Los misioneros, acompañados por pequeños grupos de soldados con una tecnología militar superior, pudieron intimidar a los nativos, y pequeñas muestras de fuerza aplastaron por completo los intentos de resistencia organizados por los chamanes, tradicionales figuras de influencia que siempre procuraban ser desplazados por parte de los misioneros. Los neófitos pudieron haber visto a los jesuitas, franciscanos o dominicos como poderosos hechiceros que fácilmente eliminaban, u obligaban a sus chamanes a ocultarse y practicar secretamente sus tradiciones religiosas. El reto más serio que se le presentó al nuevo orden ocurrió en el sur de Baja California, con unas rebeliones que sucedieron en la década de 1730 y 1740.

Numerosos factores militaban en contra de la resistencia nativa hacia las misiones. En las primeras décadas de su operación, como se señaló anteriormente, la mayoría de la población indígena continuaba residiendo en sus asentamientos tradicionales con muy poca supervisión. Inclusive con la presencia de entrenados catequistas, el proceso de aculturación fue lento. Por otra parte, existían beneficios en la asociación con la misión. Los misioneros traían nuevas fuentes de comida que proveían una forma de vida más estable para aquellos neófitos que residían en la cabecera. Los misioneros también pudieron haber abastecido de carne a los neófitos que vivían fuera de la cabecera.

La historia en la misión Rosario, en el Golfo de Texas, fue muy distinta. Los franciscanos intentaron aculturar a los Karankawas, lo que incluía cambios en su organización social, perspectiva del mundo, prácticas y creencias religiosas, e inclusive, hábitos de trabajo. Como punto central del proyecto de la misión estaba la conversión religiosa, que incluía conocimientos básicos de la doctrina católica, casi siempre enfatizando la memorización de oraciones. Solís describió los esfuerzos del misionero José Escovar, O.M.F., por instruir a los neófitos en los misterios de lo que el franciscano consideraba como la verdadera fe. Según Solís, Escovar

les enseña a rezar, se empeña en instruirlos al catecismo y a las doctrinas de nuestra fe sagrada, los impulsa a obedecer sus obligaciones civiles, les suministra comida y ropa y los ayuda en todas sus necesidades, tanto espirituales como corporales. Luego de la puesta del sol, y antes de las oraciones de la noche, los reúne en el cementerio, a grandes y pequeños, con el sonido de una campana. Les hace decir sus oraciones y recitar la doctrina cristiana; les explica e intenta instruirlos en los misterios de nuestra santa fe, incitándolos a observar los mandamientos de Dios y de nuestra Iglesia sagrada, y les enseña las cosas 
necesarias para la salvación. Cada Domingo los llama y les hace recitar el Rosario, con todos los misterios, y les hace cantar el Alabado. Antes de las misas de los domingos y días de fiestas, les hace recitar sus oraciones y las lecciones del catecismo, y luego de la misa predica y les explica la doctrina cristiana y las cosas que deberían saber y entender.

La caracterización de la relación entre los misioneros y los nativos realizada por Solís retrata el típico paternalismo que buscaban los proyectos misionales. El misionero sabía qué era lo mejor para el indígena. Al mismo tiempo, los franciscanos no reconocieron las limitaciones de una instrucción religiosa. El lenguaje fue la más difícil barrera para una conversión religiosa, sobre todo cuando uno considera que los más importantes conceptos de la religión cristiana, como Dios o la resurrección de Cristo, traen consigo una serie de significados culturalmente integrados. En otras palabras, estos conceptos tienen claros significados en la tradición judeocristiana, pero a menudo no tienen términos equivalentes en otras culturas. Es más, la confianza en la memorización de las oraciones y del catecismo no significó una conversión religiosa, y ya he discutido en otra parte que para los Karankawas, el bautizo pudo haber sido simplemente un requisito para vivir en las misiones y recibir comida. ${ }^{60}$

La realidad era que gran parte de la cultura nativa, y particularmente las prácticas y creencias religiosas, sobrevivían en las misiones. Solís reportó la persistencia de bailes tradicionales con significados religiosos entre los indígenas que vivían en la misión. Estos bailes fueron considerados como un problema, de la misma manera que sucedió en la misión de San José:

Son muy aficionados a una serie de bailes que ellos llaman mitotes. Estos mitotes expresan júbilo y alegría o tristeza y dolor, dependiendo del instrumento que los acompaña. En los bailes festivos, tocan algo así como una pandereta, un carey, la mitad de una calabaza, una olla francesa, una flauta de caña o un ayacascle. Los bailes que expresan sentimientos de dolor son acompañados por un cayman, instrumento que emite sonidos lúgubres y sin armonía. La música es acompañada por chillidos espantosos y antinaturales, y los bailadores hacen gestos y muecas, retuercen sus cuerpos de maneras extrañas y saltan y brincan mientras se mueven en formas circulares. Para sus mitotes hacen grandes fogatas y bailan alrededor de ésta, noche y día, sin ninguna interrupción. Estos mitotes duran tres días y tres noches... Durante la ceremonia los hombres parecen demonios ya que hacen horribles muecas; son pintados con rojo brillante o colores negros, $\mathrm{y}$ tienen anillos alrededor de sus ojos inyectados de sangre. Tienen varios santos, en cuyo honor llevan a cabo estos mitotes; uno es el dios Pichini; otro el santo Mel. A éstos les

${ }^{60}$ Jackson, "Congregation and Population Change." 
piden, mediante sus bailes supersticiosos, la victoria sobre sus enemigos, éxito en sus campañas, cosechas abundantes o buena suerte en la caza de venados, bisontes y osos. ${ }^{61}$

Los mitotes eran elementos centrales en los rituales religiosos de los Karankawas; tan importantes que persistieron luego de establecidas las misiones. Los franciscanos intentaron, no siempre con éxito, promover otro tipo de bailes y de representaciones religiosas.

Los neófitos también resistieron el régimen de las misiones. La forma más común de resistencia era irse de las misiones. En 1779 hubo un intento de insurrección, que tuvo como consecuencia el abandono de la misión Rosario por parte de los neófitos. Luego de la insurrección, los franciscanos abandonaron la misión durante una década. Según una fuente, un neófito aculturado que hablaba español convenció a los demás de abandonar la misión. En 1790, Fr. Reyes, quien residía en Rosario desde el año anterior, señaló que los indígenas "se fueron a la costa en 1779 como consecuencia de los crueles e irrazonables castigos que les imponía el difunto Capitán Carloza y su Teniente, Don José Santoja [del Presidio de La Bahía] y también porque los Padres Ministros, también difuntos, querían restringir y despojar a los indígenas de su libertad." ${ }^{\text {,2 }}$ Al final de la década de 1770, los esfuerzos por cambiar a los Karankawas terminaron en una insurrección y un abandono a gran escala de la misión. La insurrección fue liderada por la segunda generación de neófitos, que ya habían sido expuestos al programa de Rosario.

De igual manera, el trato que recibieron los Karankawas en la misión Rosario fue lo que provocó la revuelta de 1779, la misma que obligó a los franciscanos a abandonarla durante una década. Solís reportó en 1768 la persistencia de los bailes rituales en Rosario. Es posible que la revuelta de 1779 haya sido la respuesta a los esfuerzos de los misioneros por eliminar los bailes, por interrumpir los patrones de migración estacional y por organizar a los Karankawas como una disciplinada mano de obra. Un franciscano señaló, en 1790, las causas de la revuelta: la forma como el comandante del Presidio de La Bahía y los mismos franciscanos trataron a los neófitos.

\section{Conclusiones}

\footnotetext{
${ }^{61}$ Forrestal, "Solís Diary."

${ }^{62}$ Citado en Gilmore, "Indians of Mission Rosario," 165.
} 
Los jesuitas, franciscanos y dominicos asignados para las misiones del norte de México se encontraron con una variedad de pueblos, desde los agricultores sedentarios de Nuevo México hasta los cazadores-recolectores nómadas de Baja California y de la región del Golfo de México en Texas. El proyecto de la misión pudo haber sido muy bueno en teoría, pero los misioneros se tropezaron con numerosas dificultades cuando tuvieron que tratar con "pueblos errantes" que tendían a desobedecer a los misioneros, y con ambientes áridos que limitaban su habilidad para establecer comunidades indígenas estables basadas en la agricultura. El comportamiento colectivo de grupos como los Karankawas, y las áridas tierras del Desierto Central de Baja California, presentaron retos únicos y diferentes a los españoles. Para poder entender los altibajos históricos de la relación entre los misioneros y los "pueblos errantes" es necesario proveer evidencia detallada de estas diversas interacciones.

Las misiones establecidas por los jesuitas y franciscanos en el Desierto Central de Baja California se toparon con un inconveniente que les hizo modificar su proyecto: la falta de agua para la agricultura, que les impidió congregar a los nativos en grandes comunidades. En cambio, los misioneros incorporaban a los neófitos al nuevo orden colonial mediante el bautismo, un acto simbólico, y luego dejaban que los neófitos se defendieran por sí solos sin ningún tipo de supervisión. Aunque los misioneros, particularmente los jesuitas, escribieron en un tono de auto felicitación con respecto al éxito de la conquista espiritual de los nativos, la realidad era muy diferente. La conversión religiosa fue superficial, ya que se daba tan sólo una apariencia de lo que era el cristianismo, una apariencia que era muy tenue.

Los Karankawas de la costa del golfo en Texas representaron un reto para los misioneros franciscanos, quienes abiertamente expresaron su frustración al no poder cambiar las formas de vida de este "pueblo errante." Los Karankawas tenían un definido patrón de migración estacional para explotar fuentes de comida, como lo hicieron los nativos que vivían en el Desierto Central de Baja California. Los misioneros franciscanos ofrecieron poco de lo que los Karankawas necesitaban y no podían tomar. Los rebaños de animales reemplazaron a los venados y búfalos que los Karankawas anteriormente cazaban, pero fue sencillo para los nativos cazar el ganado de las misiones, en vez de los más ariscos venados o búfalos. Los neófitos Karankawas iban y venían de las misiones según las estaciones, y los franciscanos no podían depender de los militares para forzar a los nativos a vivir de una manera sedentaria. 
He utilizado libremente el término "pueblos errantes" de Radding en este ensayo, para recalcar una o dos cuestiones historiográficas. La primera es que los españoles tuvieron que enfrentarse con muchos "pueblos errantes" que estaban situados en los límites del norte de México, y las experiencias de los misioneros con ellos variaban de región a región. El entorno fue uno de los factores que influyó en la diversidad de experiencias históricas. La discusión acerca de estos pueblos y las "fronteras ecológicas" en la historia de los intercambios entre indígenas y españoles durante el periodo colonial en la frontera norte de México, no es nueva por ningún motivo. ${ }^{63}$

\footnotetext{
${ }^{63}$ Dos ejemplos recientes de esta literatura acerca de Baja California son Peveril Meigs, The Dominican Mission Frontier of Lower California (Berkeley: University of California Press, 1935); Aschmann, Central Desert of Baja California.
} 